\title{
DETERMINATION OF ALUMINA AND SILICA IN STEEL BY THE HYDROCHLORIC ACID RESIDUE METHOD
}

\author{
By J. G. Thompson and J. S. Acken
}

ABSTRACT

The hydrochloric acid residue method, as used at the Bureau of Standards for the determination of alumina and silica in steels, is described. Analyses of six steels indicate that this method yields results for both alumina and silica which compare favorably with those obtained by the bromine and nitric acid residue methods. Of the three methods, the hydrochloric acid method is preferred on the grounds of speed and simplicity of operation.

Data are presented to show that the presence of aluminum nitride in a steel does not cause appreciable errors in the determination of alumina by the hydrochloric acid residue method.

The recovery of manganese oxide and silica from manganese silicates, by means of the hydrochloric-acid-residue method, is discussed. Data are presented to show that satisfactory recovery of silica is obtained only from silicates rich in silica and that satisfactory recovery of manganese oxide is not obtained by this method.

\section{CONTENTS}

I Introduction

II Methods of analysis

III Experimental results

1. Behavior of aluminum nitride in the determination of alumina..

2. Comparison of results obtained from different residue methods -

3. Recovery of silica and manganous oxide from synthetic manga-

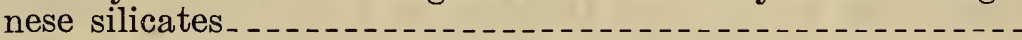

IV Summary

\section{INTRODUCTION}

The use of dilute hydrochloric acid to effect the separation of metallic and nonmetallic constituents of steel was first applied to the determination of alumina in steel by Kichline ${ }^{1}$ who reported that not more than 1 or 2 per cent of the alumina $\left(\mathrm{Al}_{2} \mathrm{O}_{3}\right)$ present is soluble in dilute hydrochloric acid. He recommended decomposition of the sample in diluted acid $(2+3)$ with subsequent determination of alumina in the residue by the phosphate method.

Oberhoffer and Ammann ${ }^{2}$ confirmed Kichline's conclusions regarding the insolubility of alumina in diluted hydrochloric acid and presented comparative analyses made by the bromine method and by the hydrochloric-acid method. The results obtained by the two methods are in satisfactory agreement, although the values obtained by the bromine method usually are slightly higher than those obtained by the hydrochloric-acid method.

1 F. O. Kichline, Note on the Determination of Aluminum Oxide and Total Aluminum in Steel, J. Ind. Eng. Chem., vol. 7, pp. 806-807, 1915.

2 P. Oberhoffer and E. Ammann, Ein Beitrag zur Bestimmung Oxydischer Einschlüsse in Roheisen und Stahi, Stabl u. Eisen, vol. 47, pp. 1536-1540, 1927. 
At the Bureau of Standards it was found that the hydrochloric-acidresidue method could be modified to permit the determination of silica $\left(\mathrm{SiO}_{2}\right)$ as well as alumina. The principal modification consists in the use of the 3 per cent sodium carbonate washing solution which Oberhoffer and Ammann employed to separate silica and hydrated silicic acid in the residues obtained in their modified bromine method. The silica in the residue originates in silica and silicate inclusions in the steel. The hydrated silicic acid originates in the decomposition of metallic silicides, and must be separated from the silica before an accurate determination of the latter can be made. The residue which remains after treatment with the acid and alkali solutions may be analyzed by several methods, but it is believed that a complete description of the procedure in use at the Bureau of Standards will be of interest. This procedure is described in the succeeding section.

\section{METHODS OF ANALYSIS}

\section{DETERMINATION OF SILICA AND ALUMINA}

Dissolve $50 \mathrm{~g}$ of steel chips in $500 \mathrm{ml}$ of diluted hydrochloric acid $(1+2)$ on the steam bath. After solution of the iron is complete, filter, with moderate suction, through a tight paper containing a little ashless paper pulp. Wash the residue ${ }^{3}$ on the filter several times with cold water or with diluted hydrochloric acid $(1+20)$ and then with hot water until the filter paper is free from iron salts. Wash the residue further with $500 \mathrm{ml}$ of hot $\left(80^{\circ}\right.$ to $90^{\circ}$ C.) 3 per cent sodium carbonate solution, followed by successive washings with hot water, $50 \mathrm{ml}$ of diluted hydrochloric acid $(1+20)$ and finally with hot water. The diluted hydrochloric acid removes hydrated iron salts and any sodium silicate which may have formed in dissolving the hydrated silicic acid.

Transfer the paper and residue to a platinum crucible,$^{4}$ and heat gently so as to char the paper without allowing it to flame. Finally increase the temperature and ignite, under good oxidizing conditions, but do not let the temperature rise above very dull redness (about $\left.600^{\circ} \mathrm{C}\right)$. Fuse with a small amount of sodium carbonate $(2 \mathrm{~g}$ will usually suffice). Cool, and dissolve in $50 \mathrm{ml}$ of diluted hydrochloric acid $(1+10)$. If a residue remains, filter and wash. Reserve the filtrate designating it $(A)$. Ignite paper and residue in a platinum crucible, fuse with $3 \mathrm{~g}$ of potassium pyrosulphate, dissolve the cooled melt in a small volume of dilute hydrochloric acid and add to the reserved filtrate $(A)$.

Silica.-Evaporate the solution $(A)$ to dryness and bake for one hour at $105^{\circ} \mathrm{C}$. Cool, drench with $10 \mathrm{ml}$ of hydrochloric acid and digest a few minutes. Add $75 \mathrm{ml}$ of warm water to dissolve salts, filter, and wash several times with cold diluted hydrochloric acid $(1+10)$ and then with warm water. Reserve the filtrate, designating it $(B)$. Ignite the paper and contents in a platinum crucible, slowly at first, and finally at a temperature of $1,200^{\circ} \mathrm{C}$. for about 25 minutes. Cool, weigh, volatilize silica by the usual hydrofluoric-sulphuric acid treatment and reweigh. Any residue remaining in the crucible is dissolved in hydrochloric acid, or fused with bisulphate and added to the reserved filtrate $(B)$.

3 The residue may contain carbides of alloying elements, such as chromium and vanadium.

4 With some steels, such as those which contain appreciable amounts of copper, it is advisable to ignite (not over $600^{\circ} \mathrm{C}$.) in porcelain and subsequently transfer the residue to platinum for the fusion treatments. 
Alumina.-Adjust the volume of the filtrate $(B)$ to about $100 \mathrm{ml}$, add $2 \mathrm{ml}$ of strong sulphurous acid, ${ }^{5}$ and boil vigorously to expel the excess sulphur dioxide. Add $4 \mathrm{ml}$ of concentrated nitric acid to the hot solution and boil to oxidize ferrous iron. Add sodium hydroxide solution until the acid solution is nearly neutral. Pour the nearly neutral solution slowly and with constant stirring into $80 \mathrm{ml}$ of an 8 per cent solution of sodium hydroxide. Heat to boiling, remove from the source of heat, and allow to stand for at least two hours to permit the precipitate to settle. Filter through a double filter of a strong tight paper (No. 42 Whatman), and wash with a 1 per cent solution of sodium hydroxide.

Acidify the filtrate with hydrochloric acid and concentrate to a volume of about $250 \mathrm{ml}$. Add $5 \mathrm{ml}$ of concentrated hydrochloric acid and $0.5 \mathrm{~g}$ of diammonium phosphate. The addition of a little macerated filter paper will prevent gelatinous aluminum phosphate, formed subsequently, from coagulating in lumps which are difficult to wash free from sodium and ammonium salts. Add two drops of methyl red indicator, make the solution just ammoniacal and restore the pink color with several drops of diluted hydrochloric acid $(1+20)$. Heat the solution to boiling, add $20 \mathrm{ml}$ of a 20 per cent solution of ammonium acetate and boil for five minutes. Let stand for 1 to 2 hours, filter through a tight $9 \mathrm{~cm}$ paper (No. 42 Whatman) and wash with hot 5 per cent solution of ammonium nitrate until $10 \mathrm{ml}$ of the washings no longer yield a test for chlorides with acidified silver nitrate. Ignite the residue and paper in platinum under good oxidizing conditions until carbon is gone; cover, and heat at about $1,000^{\circ} \mathrm{C}$, to constant weight. The observed weight of aluminum phosphate multiplied by the factor 0.418 is recorded as the weight of $\mathrm{Al}_{2} \mathrm{O}_{3}$ present in the original residue. Blank determinations are made on all reagents used, and the proper corrections are applied to the results of each analysis.

\section{DETERMINATION OF MANGANOUS OXIDE}

Any manganese present in the original residue will be found with the iron and chromium precipitated by the sodium hydroxide treatment. If manganese is to be determined, dissolve this precipitate of iron, chromium, and manganese with $50 \mathrm{ml}$ of warm diluted nitric acid $(1+3)$ containing a few milliliters of sulphurous acid. Boil the solution to expel the oxides of nitrogen, allow to cool, and determine manganese by the bismuthate method. If the amount of manganese is very small it is better to use the periodate colorimetric method. ${ }^{6}$

\section{EXPERIMENTAL RESULTS}

\section{BEHAVIOR OF ALUMINUM NITRIDE IN THE DETERMINATION OF ALUMINA}

The question arose whether aluminum nitride, if present in the steel, would be found in the acid-insoluble residue and carried through the determination and reported as alumina. To investigate this possi-

\footnotetext{
8 The sulphurous acid, made by passing sulphur dioxide into distilled water to saturation, is added to reduce any oxidized chromium in order that all of the chromium present may be removed subsequently with the iron. The reduction of chromium by means of hydrogen peroxide was tried, but difficulty was encountered in the subsequent removal of iron from the solution, perhaps due to the formation of small amounts of soluble sodium ferrate.

H. H. Willard and L. H. Greathouse, The Colorimetric Determination of Manganese by Oxidation with Periodate. J. Am. Chem. Soc., vol. 39, pp. 2366-2376, 1917.
} 
bility, a quantity of aluminum nitride, containing 10.1 per cent nitrogen, was obtained through the courtesy of the Fixed Nitrogen Research Laboratory, of the U. S. Department of Agriculture.

Two portions of approximately $50 \mathrm{mg}$ each were treated in separate beakers with $50 \mathrm{ml}$ of diluted hydrochloric acid $(1+2)$. After standing on the steam bath overnight, the solutions were filtered and the residues on the filter papers were washed as in the regular procedure for the separation of acid-insoluble residues. The residues were ignited at a dull red heat to destroy carbonaceous matter, cooled, and transferred together with $50 \mathrm{ml}$ of hydrochloric acid $(1+1)$ to distilling flasks for the determination of nitrogen by the Allen method. Nitrogen is the only constituent of aluminum nitride which was determined, as it was assumed that any attack on the nitrides, by either acid or alkaline solutions, which resulted in solution of the nitrogen, would result in the simultaneous solution of an equivalent amount of aluminum. In other words, if nitrogen dissolves from aluminum nitride, in either acid or alkaline solutions, aluminum likewise will dissolve.

The data obtained from these two samples showed that the insoluble residues contained less than 4 per cent of the nitrogen present in the original samples. This indicates that at least 96 per cent of syñthetic aluminum nitride is soluble in the hydrochloric acid $(1+2)$ or in the wash solutions.

In addition to the above, tests were also made on nitrided samples of two commercial steels, one of the aluminum-molybdenum type and the other of the aluminum-molybdenum-chromium type, obtained through the courtesy of Dr. V. O. Homerberg. The composition of these steels prior to nitriding is recorded in Table 1. Specimens for residue analysis consisted of thin nitrided disks, approximately onesixteenth inch thick and five-eighths inch in diameter, chosen on the assumption that with such thin sections practically all of a specimen would be affected by the nitriding treatment.

Samples of each nitrided steel were subjected to the different operations of a residue analysis, as follows: The samples designated $A$ in Table 1 were decomposed in hydrochloric acid $(1+2)$, filtered, and the acid-insoluble residues were washed with the customary solutions. Nitrogen was determined separately in the original filtrates, in the wash waters, and in the unignited residues. The samples designated $B$ in Table 1 were decomposed in hydrochloric acid $(1+2)$, filtered without washing, and nitrogen was determined in the filtrates and residues.

The results recorded in Table 1 show that the nitrides present in these two nitrided steels were almost completely decomposed and dissolved by the first solution treatment with hydrochloric acid $(1+2)$ in the usual procedure of residue analysis. The amounts of nitrogen recovered either from the wash waters or from the insoluble residues were of approximately the order of magnitude of the blank correction. However, small but positive traces of nitrogen usually were indicated, as recorded in Table 1 . These data show that the amounts of nitrides which survived the solution in acid but dissolved in the wash waters were negligible. The amounts of nitrides retained in the insoluble residues in all cases were an insignificant proportion of the nitrides present in the original sample. 
TABLE 1.-Behavior of nitrides in residue analysis of two nitrided steels

\begin{tabular}{|c|c|c|c|c|}
\hline \multirow[b]{2}{*}{ Sample No. } & \multirow[b]{2}{*}{$\begin{array}{l}\text { Weight of } \\
\text { sample }\end{array}$} & \multicolumn{3}{|c|}{ Nitrogen recovered } \\
\hline & & Filtrate & $\begin{array}{l}\text { Wash } \\
\text { waters }\end{array}$ & Residue \\
\hline $\begin{array}{l}225 \mathrm{~A}-1 \\
225 \mathrm{~A} \\
2257 \mathrm{~B}\end{array}$ & $\begin{array}{l}g \\
5.858 \\
4.613 \\
6.174 \\
5.247\end{array}$ & $\begin{array}{c}g \\
0.1000 \\
.0720 \\
.1115 \\
.0870\end{array}$ & $\begin{array}{r}0.00008 \\
\text { Nil. }\end{array}$ & $\begin{array}{l}g \\
0.0002 \\
.00014 \\
.00007 \\
.0002\end{array}$ \\
\hline
\end{tabular}

COMPOSITION OF STEELS BEFORE NITRIDING

\begin{tabular}{|c|c|c|c|c|c|c|c|c|}
\hline Steel No. & $\mathrm{C}$ & $\mathrm{Mn}$ & $\mathbf{P}$ & $\mathrm{s}$ & $\mathrm{Si}$ & $\mathrm{Al}$ & Mo & $\mathrm{Cr}$ \\
\hline $\begin{array}{l}225-- \\
2257_{-}\end{array}$ & $\begin{array}{r}\text { Per cent } \\
0.19 \\
.35\end{array}$ & $\begin{array}{r}\text { Per cent } \\
0.38 \\
.48\end{array}$ & $\begin{array}{r}\text { Per cent } \\
0.014 \\
.018\end{array}$ & $\begin{array}{r}\text { Per cent } \\
0.012 \\
.020\end{array}$ & $\begin{array}{r}\text { Per cent } \\
0.16 \\
.15\end{array}$ & $\begin{array}{r}\text { Per cent } \\
1.88 \\
.90\end{array}$ & $\begin{array}{r}\text { Per cent } \\
0.83 \\
.20\end{array}$ & Per cent \\
\hline
\end{tabular}

It is concluded, therefore, that the small amounts of aluminum nitride ordinarily present in nonnitrided steels (or in the interior portions of nitrided ones) do not interfere with the determination of alumina by the hydrochloric acid residue procedure. However, in the case of nitrided steels if we assume that all residual nitrogen was present as aluminum nitride and calculate to the equivalent $\mathrm{Al}_{2} \mathrm{O}_{3}$ we find an appreciable error would occur in the determination of $\mathrm{Al}_{2} \mathrm{O}_{3}$, particularly if the latter were present in very small amounts.

\section{COMPARISON OF RESULTS OBTAINED FROM DIFFERENT RESIDUE METHODS}

The data in .Table 2 are the results obtained for alumina and silica in comparative analyses of six steels by the nitric acid, ${ }^{7}$ the bromine, and the hydrochloric acid residue methods.

The results obtained for alumina are in satisfactory agreement for all three methods. It is believed, however, that the hydrochloric acid residue method is preferable, as it is more rapid and more convenient to operate than either the nitric acid or the bromine methods.

In the determination of silica, the results from the modified hydrochloric acid method and the bromine method are in satisfactory agreement, but some of the results from the nitric acid method are lower than results from either of the other two. The lower results from the nitric acid method probably can be explained on the basis of Oberhoffer and Ammann's statement that the sodium hydroxide wash used in the nitric acid method not only dissolves hydrated silicic acid but also attacks dehydrated silica.

rJ. H. S. Dickenson, A Note on the Distribution of Silicates in Steel Ingots, J. Iron \& Steel Inst., vol. 113 (No. 1), pp. 177-196, 1926. 
TABLE 2.-Comparison of results obtained by different residue methods for alumina and silica

\begin{tabular}{|c|c|c|c|c|c|c|c|c|}
\hline \multirow[b]{2}{*}{ Туре of steel } & \multirow[b]{2}{*}{$\begin{array}{l}\text { Sample } \\
\text { No. }\end{array}$} & \multirow[b]{2}{*}{$\begin{array}{l}\text { Mold additions for } 3 \\
\text { tons of steel }\end{array}$} & \multicolumn{3}{|c|}{$\mathrm{Al}_{2} \mathrm{O}_{3}$} & \multicolumn{3}{|c|}{$\mathrm{SiO}_{2}$} \\
\hline & & & $\begin{array}{l}\text { Hydro- } \\
\text { chloric- } \\
\text { acid } \\
\text { method }\end{array}$ & $\begin{array}{l}\text { Brom- } \\
\text { ine } \\
\text { meth- } \\
\text { od }^{1}\end{array}$ & $\begin{array}{l}\text { Nitric- } \\
\text { acid } \\
\text { meth- } \\
\text { od } 1\end{array}$ & $\begin{array}{l}\text { Hydro- } \\
\text { chloric- } \\
\text { acid } \\
\text { method } \\
\text { (modi- } \\
\text { fied) }\end{array}$ & $\begin{array}{l}\text { Bro- } \\
\text { mine } \\
\text { meth- } \\
\text { od } 1\end{array}$ & $\begin{array}{l}\text { Nitric- } \\
\text { acid } \\
\text { meth- } \\
\text { od } 1\end{array}$ \\
\hline $\begin{array}{l}\text { Killed steel }(0.14 \quad \mathrm{C} \text {, } \\
0.44 \mathrm{Mn}, 0.15 \mathrm{Si})\end{array}$ & $\begin{array}{l}113 \\
119 \\
122\end{array}$ & $\begin{array}{l}4 \text { pounds } \mathrm{Al} \\
25 \text { pounds } \mathrm{Fe}-\mathrm{V} \\
\text { None. }\end{array}$ & $-\begin{array}{c}\text { Per cent } \\
0.026 \\
.003 \\
.002\end{array}$ & $\begin{array}{c}\text { Per cent } \\
0.023 \\
.002 \\
.002\end{array}$ & $\begin{array}{c}\text { Per cent } \\
0.022 \\
.003 \\
.001\end{array}$ & $\begin{array}{c}\text { Per cent } \\
0.001 \\
.004 \\
.008\end{array}$ & $\begin{array}{c}\text { Per cent } \\
0.002 \\
.006 \\
.006\end{array}$ & $\begin{array}{r}\text { Per cent } \\
<0.001 \\
.002 \\
.002\end{array}$ \\
\hline $\begin{array}{l}\text { Efiervescing steel }(0.14 \\
\mathrm{C}, 0.42 \mathrm{Mn}, 0.003 \mathrm{Si})\end{array}$ & $\begin{array}{l}125 \\
131 \\
134\end{array}$ & $\begin{array}{l}4 \text { pounds Al } \\
25 \text { pounds } \mathrm{Fe}-\mathrm{V} \\
\text { None- }\end{array}$ & $\begin{array}{l}.014 \\
.002 \\
.001\end{array}$ & $\begin{array}{l}.016 \\
.002\end{array}$ & $\begin{array}{r}.017 \\
<.001 \\
<.001\end{array}$ & $\begin{array}{l}<.001 \\
<.008 \\
<.001\end{array}$ & $\begin{array}{l}.001 \\
.009\end{array}$ & $\begin{array}{r}.001 \\
<.01 \\
<.001\end{array}$ \\
\hline
\end{tabular}

1 Analyses by the bromine method were made by R. J. Kranauer, formerly of the Bureau of Standards. Analyses by the nitric-acid method were made by H. A. Bright.

\section{RECOVERY OF SILICA AND MANGANOUS OXIDE FROM SYNTHETIC MANGANESE SILICATES}

In analyses of acid-insoluble residues by the hydrochloric acid method, it was frequently observed that the sodium carbonate fusions were colored green, indicating the presence of manganese. It is probable that manganous oxide, if present in the steel, would be soluble in hydrochloric acid $(1+2)$, but it is possible that certain manganese silicates, if present, would be insoluble and, therefore, would appear in the residue. In order to investigate this possibility, synthetic manganese silicates containing different proportions of manganous oxide and silica were prepared, and the amounts of manganous oxide and silica recovered by the modified hydrochloric acid residue method were determined.

Manganous oxide was prepared in the laboratory from manganese carbonate by two methods. In one method the carbonate was oxidized to $\mathrm{MnO}_{2}$ by treatment with nitric acid. The $\mathrm{MnO}_{2}$ was reduced to $\mathrm{MnO}$ by heating in a nickel boat in a stream of hydrogen at $900^{\circ} \mathrm{C}$. for about four hours. In the other method manganese carbonate was calcined in air at about $1,200^{\circ} \mathrm{C}$. in a graphite crucible in the induction furnace, and was then further heated at $1,500^{\circ} \mathrm{C}$. in graphite in a vacuum.

Three manganese silicates, intended to contain 25,50 , and 75 per cent $\mathrm{MnO}$, respectively, were prepared by mixing precipitated manganese carbonate and pulverized quartz in the proper proportions and heating each mixture in a graphite crucible to about $1,500^{\circ} \mathrm{C}$. After cooling in the furnace the melt was cleaned on an emery wheel and then crushed and ground. In the course of the investigation it appeared that manganese silicates of additional compositions were needed. Such silicates, containing approximately 30 and 60 per cent $\mathrm{MnO}$, respectively, were supplied by Dr. C. H. Herty, jr., of the Bureau of Mines.

The manganese silicates, manganous oxide, and quartz used in the analyses were ground to pass through a No. 120 sieve. The two silicates received from Doctor Herty passed through a No. 200 sieve. Each sample for residue analysis consisted of about $10 \mathrm{mg}$ of one of the finely ground materials mixed with $50 \mathrm{~g}$ of drillings of vacuum- 
fused electrolytic iron. Fifty-gram portions of drillings, without additions, frequently were run as blank determinations.

The results obtained for the recovery of manganous oxide and silica from these synthetic manganese silicates, by the modified hydrochloric acid residue method, are presented in Table 3 and are shown graph-

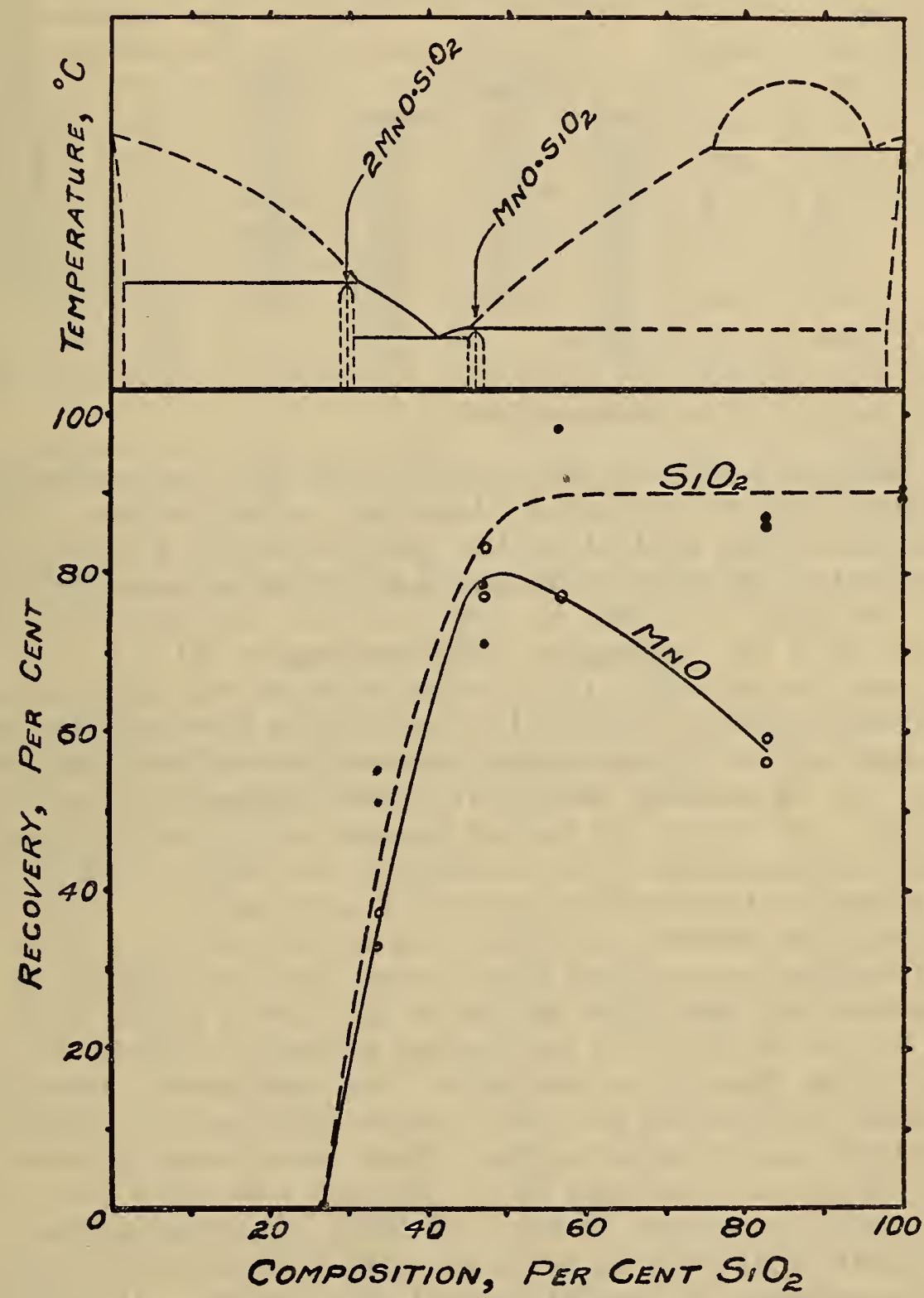

Figure 1.-Recovery of $\mathrm{MnO}$ and $\mathrm{SiO}_{2}$ from synthetic manganese silicates by the hydrochloric acid residue method

ically in Figure 1. The equilibrium diagram for the system $\mathrm{MnO}-$ $\mathrm{SiO}_{2}^{89}$ is included in Figure 1 for convenience in interpreting the results.

${ }^{8} \mathrm{C}$. Benedicks and H. Löfquist, Nonmetallic Inclusions in Iron and Steel, Chapman \& Hall, London, p. 98,1930 .

p. 98 C. H. Herty, jr., and G. R. Fitterer, New Manganese Silicon Alloys for the Deoxidation of Steel, U. S. Bureau of Mines Report of Investigations, R. I. $3081,1931$. 
TABLE 3.-Recovery of $\mathrm{MnO}$ and $\mathrm{SiO}_{2}$ from synthetic manganese silicates

\begin{tabular}{|c|c|c|c|c|c|c|c|}
\hline \multicolumn{2}{|c|}{$\begin{array}{l}\text { Composition of } \\
\text { sample }\end{array}$} & \multicolumn{2}{|c|}{ Weight taken } & \multicolumn{2}{|c|}{ Weight found } & \multicolumn{2}{|c|}{ Recovery } \\
\hline $\mathrm{MnO}$ & $\mathrm{SiO}_{2}$ & $\mathrm{MnO}$ & $\mathrm{SiO}_{2}$ & $\mathrm{MnO}$ & $\mathrm{SiO}_{2}$ & $\mathrm{MnO}$ & $\mathrm{SiO}_{2}$ \\
\hline $\begin{array}{c}\text { Per cent } \\
0 .\end{array}$ & $\begin{array}{c}\text { Per cent } \\
100\end{array}$ & $g$ & $\left\{\begin{array}{c}g \\
0.0104\end{array}\right.$ & & 0. $\stackrel{g}{0093}$ & Per cent & $\begin{array}{c}\text { Per cent } \\
89\end{array}$ \\
\hline 16.4 & 82.7 & $\begin{array}{l}0.0016 \\
0017\end{array}$ & $\begin{array}{r}.01083 \\
.0084\end{array}$ & $\begin{array}{r}0.0009 \\
0010\end{array}$ & $\begin{array}{r}.0071 \\
.0073\end{array}$ & 56 & \\
\hline 130.2 & ${ }^{1} 56.3$ & .0035 & .0065 & .0027 & .0064 & $\begin{array}{l}77 \\
77\end{array}$ & \\
\hline 50.7 & 47.0 & $\left\{\begin{array}{l}.0062 \\
0053\end{array}\right.$ & .0058 & $\begin{array}{r}.0048 \\
.0044\end{array}$ & $\begin{array}{r}.0041 \\
.0038\end{array}$ & $\begin{array}{l}77 \\
83\end{array}$ & $\begin{array}{l}71 \\
78\end{array}$ \\
\hline 158.2 & 133.7 & $\left\{\begin{array}{l}.0062 \\
.0060\end{array}\right.$ & $\begin{array}{l}.0036 \\
.0035\end{array}$ & $\begin{array}{l}.0023 \\
.0020\end{array}$ & $\begin{array}{l}.0020 \\
.0018\end{array}$ & $\begin{array}{l}37 \\
33\end{array}$ & $\begin{array}{l}55 \\
51\end{array}$ \\
\hline 70.0 & 26.5 & .0070 & $\begin{array}{l}.0027 \\
.0028\end{array}$ & $\begin{array}{l}.0000 \\
.0000\end{array}$ & $\begin{array}{l}.0000 \\
.0000\end{array}$ & $\begin{array}{l}\text { Nil. } \\
\text { Nil. }\end{array}$ & $\begin{array}{l}\text { Nil. } \\
\text { Nil. }\end{array}$ \\
\hline 100.0 & 0. & $\begin{array}{l}.0109 \\
.0101\end{array}$ & & $\begin{array}{l}.0000 \\
.0000\end{array}$ & & $\begin{array}{l}\text { Nil. } \\
\text { Nil. }\end{array}$ & \\
\hline
\end{tabular}

1200 -mesh samples. Other samples were 120 mesh.

The silicates containing about 50 per cent $\mathrm{SiO}_{2}$, approximately the composition of the compound $\mathrm{MnO}^{-\mathrm{SiO}_{2}}$, were the least soluble in dilute hydrochloric acid of all the silicates in this system. As the $\mathrm{SiO}_{2}$ content of the silicates increased above 50 per cent the recovery of $\mathrm{SiO}_{2}$ remained at about 90 per cent, but the recovery of $\mathrm{MnO}$ decreased from the maximum. With decreasing $\mathrm{SiO}_{2}$ content, below 50 per cent, the solubility of the silicates increased rapidly, resulting in decreased recovery of both $\mathrm{MnO}$ and $\mathrm{SiO}_{2}$ in the insoluble residues. The sample which approximated the compound $2 \mathrm{MnO}^{-\mathrm{SiO}_{2}}$ in composition, was completely soluble in dilute hydrochloric acid, as was pure $\mathrm{MnO}$. In view of the limited number of determinations and the difficulties encountered in these analyses, too much emphasis should not be placed on the results of any one determination. However, the general relation between solubility and composition is indicated and it is interesting to note that these curves for the solubility in dilute hydrochloric acid are quite similar to the curves which Herty ${ }^{10}$ obtained for the solubility of manganese silicates in dilute nitric acid.

From these data it is concluded that satisfactory recoveries of silica, that is, about 90 per cent, can be obtained by means of the hydrochloric acid residue method, from manganese silicates which contain 50 per cent or more $\mathrm{SiO}_{2}$. Recovery of silica from silicates which contain less than 50 per cent $\mathrm{SiO}_{2}$, is not satisfactory. The data indicate that from 70 to 80 per cent of $\mathrm{MnO}$ is recovered from manganese silicates of over 50 per cent $\mathrm{SiO}_{2}$ content. It will be noted that the revovery of $\mathrm{MnO}$ in silicates of less than 50 per cent $\mathrm{SiO}_{2}$ is quite low. Obviously, the $\mathrm{HCl}$ method is not applicable to the determination of $\mathrm{MnO}$ occurring as such ( $\mathrm{MnO}$ inclusions) and yields only fair recoveries of $\mathrm{MnO}$ in manganese silicates of high silica content.

${ }^{10}$ C. H. Herty, jr., G. R. Fitterer, and J. F. Eckel, The Physical Chemistry of Steel Making: A Study of the Dickenson Method for the Determination of Nonmetallic Inclusions in Steel, U. S. Bureau of Mines, Mining, and Metallurgical Investigations Bull. No. 37, 1928. 


\section{SUMMARY}

1. The conclusions of previous investigators that the hydrochloric acid residue method yields results for alumina that are comparable with those obtained by the nitric acid and bromine methods, and that the hydrochloric acid method is preferable to the other two on the grounds of speed and simplicity in operation, have been confirmed.

2. The presence of aluminum nitride in a sample ordinarily does not cause appreciable errors in the determination of alumina by the hydrochloric acid residue method. If relatively large amounts of nitrides are present; for example, in a nitrided steel, accompanied by only a small amount of aluminum oxide, a small error due to incomplete decomposition of aluminum nitride might result in a serious error in the determination of a small amount of aluminum oxide.

3 . The modified hydrochloric acid residue method yields as satisfactory results for silica as do the nitric acid and bromine methods.

4. If manganese silicates are present in the sample, recoveries of about 90 per cent of the silica may be obtained from silicates which contain more than 50 per cent $\mathrm{SiO}_{2}$. Recovery of silica from silicates which contain less than 50 per cent $\mathrm{SiO}_{2}$ is not satisfactory. The hydrochloric acid method recovers about 70 to 80 per cent of $\mathrm{MnO}$ from manganese silicates having 50 per cent or more $\mathrm{SiO}_{2}$ content. The method is not suitable for $\mathrm{MnO}$ in silicates of less than 50 per cent $\mathrm{SiO}_{2}$.

\section{ACKNOWLEDGMENT}

Acknowledgment is made to $\mathrm{H}$. A. Bright, who is responsible for the section on methods of analysis, and who has contributed helpful advice on other phases of the work reported herein.

Washington, August 17, 1932. 